\title{
Mitigation of current harmonics in multi-drive system
}

\author{
Thamizh Thentral ${ }^{1}$, Ramya Rathakrishnan ${ }^{1}$, Velu Anbalagan ${ }^{2}$, Karthikeyan Dhandapani', \\ Usha Sengamalai ${ }^{1}$, Palanisamy Ramasamy ${ }^{1}$ \\ ${ }^{1}$ Department of Electrical and Electronics Engineering, SRM Institute of Science and Technology, Kattankulathur, India \\ ${ }^{2}$ Department of Electrical and Electronics Engineering, Navodaya Institute of Technology, Raichur, India
}

\begin{abstract}
Article Info
Article history:

Received Nov 3, 2021

Revised Jan 27, 2022

Accepted Feb 3, 2022

\section{Keywords:}

Adjustable speed drive

Diode rectifier

Direct torque control

Harmonics

Multi-drive system

Shunt active power filter

ABSTRACT

Most of the fully automated industries are mainly depending on the single and multi-drive system based on their requirements. In this paper, to investigate the power quality problems in a distributed multi drive system connected to the common uncontrolled rectifier is considered. Uncontrolled rectifier is mainly used as a front-end converter to feed direct current (DC) supply to the same rating of two voltage source inverters with induction motors as a multi-drive system. To analyse the effectiveness of the system the two drive systems are operated in different time period. Then, both are operated simultaneously to monitor the power quality issues, due to the front-end converter present in the system. In both the cases the harmonics in source current is not within the limits of IEEE recommended practices. Therefore, to reduce the harmonic content present in the current at source, a shunt active power filter is implemented. The effect of two drive systems operated at the same time is analysed first. Then, active filter is injected in between the source and the multi-drive system in parallel to improve the power quality of the grid system. The individual and multi-drive drive systems are analysed with the simulation results.
\end{abstract}

This is an open access article under the CC BY-SA license.

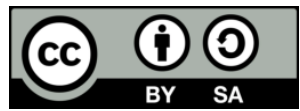

\section{Corresponding Author:}

Thamizh Thentral

Department of Electrical and Electronics Engineering, SRM Institute of Science and Technology

Kattankulathur-603203, India

Email: thentral2kuna@gmail.com

\section{INTRODUCTION}

The use of adjustable speed drive (ASD) is the major concern in many of the industries, in which the most important factor in load is harmonics and the efficiency [1]-[3] which has been always the major issue in industrial application for the power quality issue. As the system goes with the two-way process, first is converted from ac to dc by using rectification and in other stage it converts from dc to ac and sending through inverter to the induction motor load. In the first process "uncontrolled" diode rectifier (DR) [4], [5] is used because of its low cost, time of operation and the high reliability during operation, but the drawback it mitigates is increase of harmonics due to non-linear load and in the second process insulated gate bipolar transistor (IGBT) are used because of their high switching ability so that the harmonics can be reduced and thus enhancing the power quality of the system. However, during the conversion of ac to dc rectification, it brings the significant number of harmonics which distorts the power that ultimately affect the grid system. The harmonics been the major issue can bring lot of issues in the grid which are, unwanted resonance, lower the efficiency of the load and can caused malfunction at the source side.

In driving the two-drive system active power filtering method [6] is used, which is mostly in the reduction of the harmonics. Devices such as Inductor and Capacitor are used for reducing harmonics which are also known as filters, having large size used for the extensive application which required for the high- 
power devices [7], [8]. In this paper a 6-pulse rectifier is used at the front end to connect the two-alternating current (AC) drive system. The six-pulse inverter with insulated gate bipolar transistor (IGBT)switches are used to eliminate the harmonics in the source current occurred due to the bridge rectifier controlled by phase shifting mode [9] of operation. Phase shifting are done so that switching can be easily done and the mode of operation we are used is $180^{\circ}$.

To tackle the power quality issue, we have introduced the phase shift scheme, so that the current drawn from the grid is of same amount. As, result the quality of the grid system can be maximized and proper loading can be done to draw proper current and thus by increasing the efficiency of the load and reducing the distortion. A dual closed loop system is addressed here to obtain the desired speed and to reduce the complexity in controlling the speed.

Therefore, to reduce the harmonic content present in the current at source, a shunt active power filter is implemented. The effect of two drive systems operated at the same time is analysed first. Then a active filter is injected in between the source and the multi-drive system in parallel to improve the power quality of the grid system so that the efficiency is increased and harmonics can be removed from the distribution system. The individual and multi-drive drive systems are analysed with the simulation results. Section 2 describes about the multiple drive systems. The harmonics in the non-linear system is explained in section 3. Simulation results and discussion are explained in section 4 . The proposed work was concluded in section 5.

\section{ADJUSTABLE SPEED DRIVE}

Variable frequency drive (VFD) is one of the adjustable speed drives (ASD) used in industrial application for controlling the two main factors of the machine, first being is speed and other is torque. The block diagram representation of three-phase motor drive system is shown in Figure 1. The machinery in industries requires different speed for their operation so this is the reason behind the practice of ASD method for industrial application [10]. VFD plays an important role in the reduction of the harmonics, the distortion rate at the first stage is around $75 \%$, so to overcome that this method is used which is done by IGBT. The control technique with the AC reactor and direct current DC lines depends on the variation of drives voltage and power.

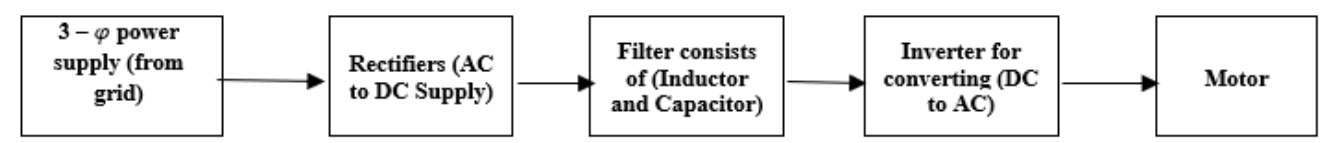

Figure 1. Three phase motor drive system

As per the requirement of the industrial application the AC drives \&DC drives are used. The purpose of using AC drives is to have good control process and minimize energy consumption for e.g. they are used in boiler feed pump and power generators and (DC) drives are used to have high starting torque and constant speed they are usually used in motors. In this paper AC drives system is used to control the speed and torque for the induction motor [11]. In VFD, effect of harmonics is more. If the VFD operates at poor power factor that decreases with decrease in motor speed, which leads to large amount of induction harmonics which supply back to the power supply, it is also caused due to non-linearity of load [12].

These are categorized into three. They are:

- Drives less than 5 HP neither have AC reactor nor DC link chokes because harmonics are negligible.

- Drives more than 5 HP requires DC link chokes for reducing harmonics.

- Drives running at $100 \mathrm{HP}$ requires AC reactor for reducing of the order $5^{\text {th }}$ and so on.

The 6-pulse rectifier is used for the reduction of low order harmonics which quiet widely used in the industrial application because of its cost and its reliability, [13] the harmonics in 6-pulse are reduced but it is not totally removed. A practice of 12 pulse rectifier, the harmonics can be reduced by some margin but the cost of using it goes high [14]. In 6-pulse rectifier the harmonics is around 16\% but when 12-pulse [15]-[18] it can be reduced to $12 \%$, so to take harmonics percentage lower Phase shift control method is used which is depicted in Figure 2. While in an 18-pulse rectifier system can also be used which can leads to even lower harmonics, but has the rectifier pulse goes higher cost rises to be used for the industrial application.

Figure 3 shows how the harmonics is getting reduced by increasing pulse of the rectifier, but gradually the cost of production goes high, also the power factor improves with the pure real power supply to the machine but does it applicable for these multi drives systems [18]. So, the harmonics distribution by the diode rectifier (DR) which produces low order harmonics, leads to poor total harmonic distortion (THD) of around $31 \%$. These can be reduced by using ASD application. 


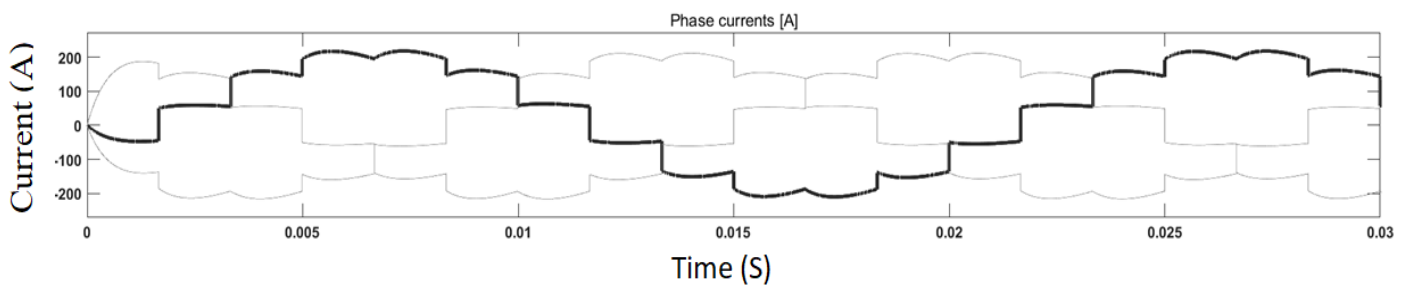

Figure 2. Current drawn for 12 pulse rectifiers

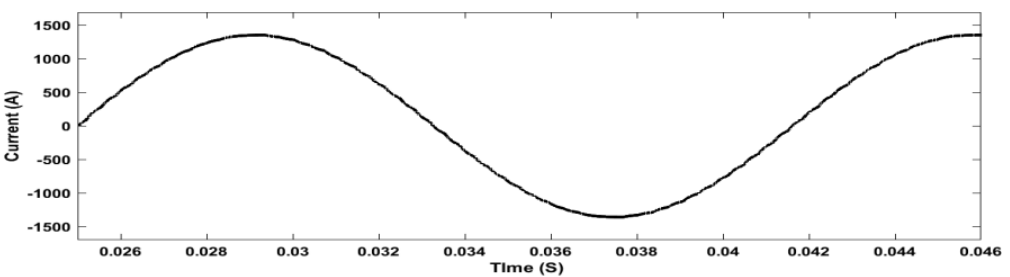

Figure 3. Current drawn for 48 pulse rectifiers

\section{ANALYSIS OF HARMONICS}

In recent years power electronic converters are wide employed in industrial as well as domestic applications for the management of power flow for automation and energy potency. Most of the time these converters draw harmonic current and reactive power from AC supply and causes the power quality issues [19], [20]. Harmonics are made by fast rise of current, either in positive or negative direction. This results to non-sinusoidal nature of the wave form of the output of an electrical converter voltage supply. Square waves and pulses wave manufacture a fast and abrupt rise during this form of wave form. Harmonics currents are the results of non-linear masses stringent a current wave form totally different from the form of applied voltage wave. The non-linear load devices include solid state power shift devices like diodes, thyristors, SCRs or transistors that convert DC power by drawing the present in pulses. These semiconductor devices form the bulk of electronic part employed in electronic devices. Harmonics in power systems are the fundamental frequencies that are multiples of first harmonic generated [21] by non-linear electrical and electronic equipment. The fundamental frequency (i.e. fifty or 60th) combines with other order harmonics to create non-sinusoidal distorted wave shapes as illustrated in Figure 4.

Harmonic current is as a result of non-linear masses stringent a current wave forms totally different from the form of applied voltage wave. Non-linear load devices are those who switch the present 'on' and 'off'. These devices include solid state power shift devices [22], [23] like diodes, thyristors, SCRs or transistors that convert DC, dc power by drawing the present in pulses. However, up to date electronic masses have totally different current and voltage shapes. For example, the voltage should still seem to be undulation, however the present wave form seems peaked, as if squeezes along. Such reasonably load contains what's known as shift power offer. Current harmonics [24], [25] are typically generated by voltage offer and depend on the sort of load like resistive load, electrical phenomenon load and inductive load each harmonic will be generated either the supply or load side. This can be the quantity of distortion made as the current flows from the facility line. The THD price [26], [27]is that the all harmonic currents additional along, compared with the fundamental current. The THD is employed to qualify the non-sinusoidal property of a wave form. This may additional be expressed because the quantitative relation of the basis means square price of all the elemental frequency.

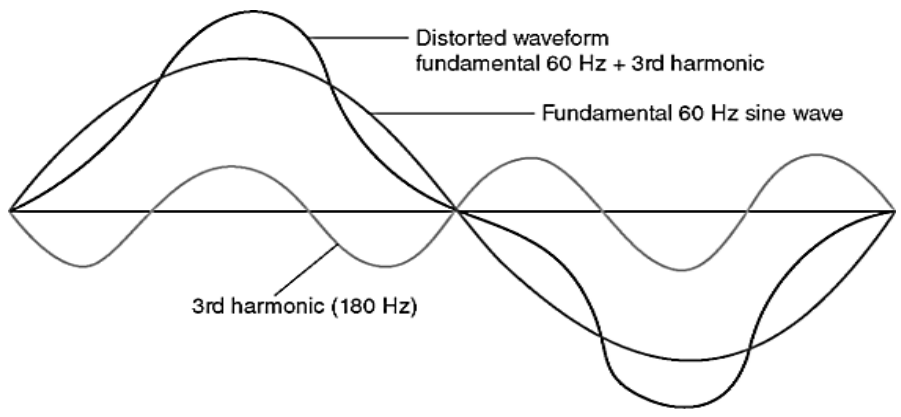

Figure 4. Harmonics in electrical waveforms 


\section{SIMULATION RESULTS AND DISCUSSION}

In order to see the current and voltage behavior when drives system is used, the proposed work is simulated and examined the effect of voltage and current at the load and source side. The three-phase non-linear system considered here is the multi drive system which is shown in Figure 5. The two alternating current (AC) induction motor drive systems with same rating are connected to the bridge rectifier in a common point. The connection of two AC drive system with common rectifier to the grid system is shown in Figure 6. Initially for 0.2 second drive system one is operated. At 0.2 second drive system two is made as ON. From 0.2 second to 0.5 second both systems are simultaneously operated.

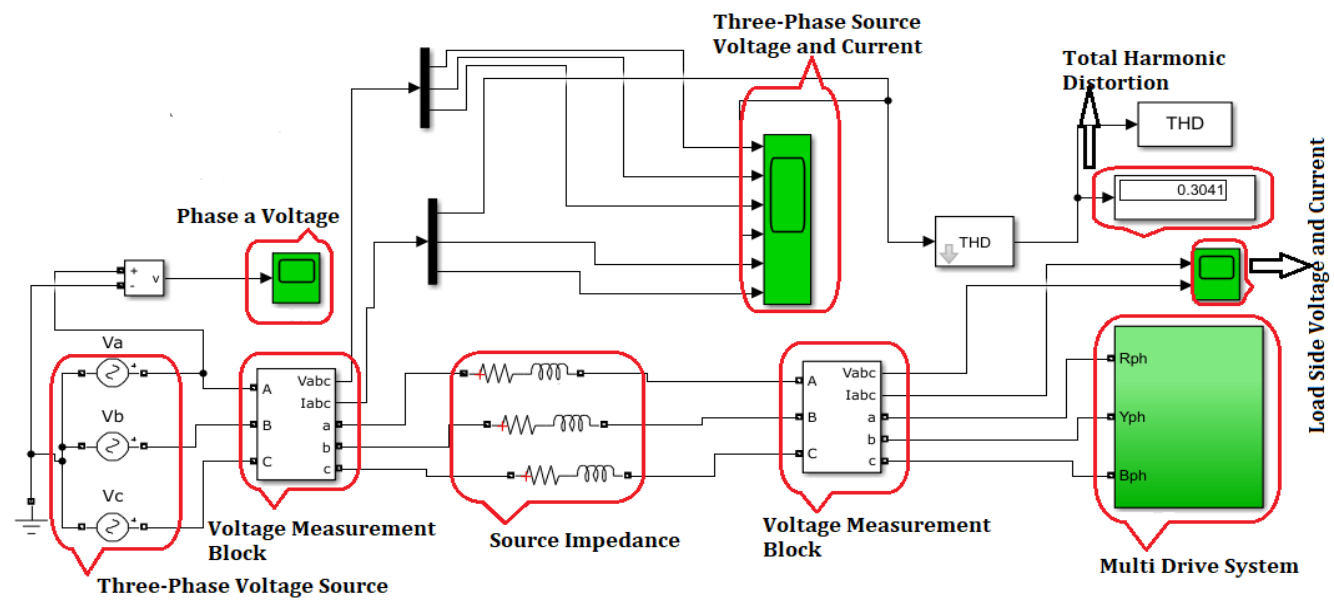

Figure 5. Three-phase non-linear system

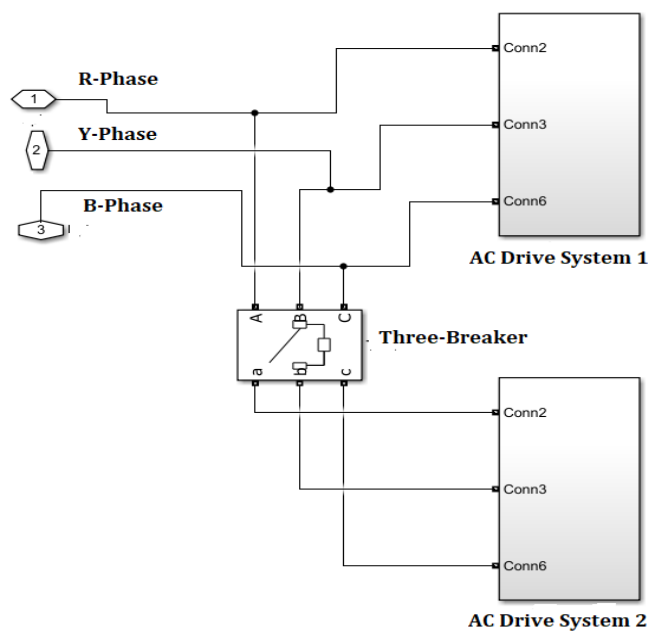

Figure 6. Multi-drive system

The source side voltage and current for the proposed three-phase multi-drive system is depicted in Figures 7 (a) and 7 (b). The voltage shown in Figure 7 (a) is constant and sinusoidal. But the current depicted in Figure 7 (b) is distorted due to the non-linearity of the system. The stringent source voltage is considered to generate the reference current.

Figure 8 depicts the voltage and current for the three-phase multi-drive system at the common point of the load side. In this also it is noticed that the voltage is constant but the current is changed according to the connection of single and multi-drive system. Figures 9 and 10 shows the output results obtained for threephase rotor current, speed and torque for the AC drive system 1 and 2 respectively. In Figure 10 depicts the rotor current for three phase, rotor speed and electromagnetic torque. When, at 0.2 second drive two is made as $\mathrm{ON}$ the rotor current is oscillated up to 0.35 second. After 0.35 second it reaches the steady state condition and maintain constant. 

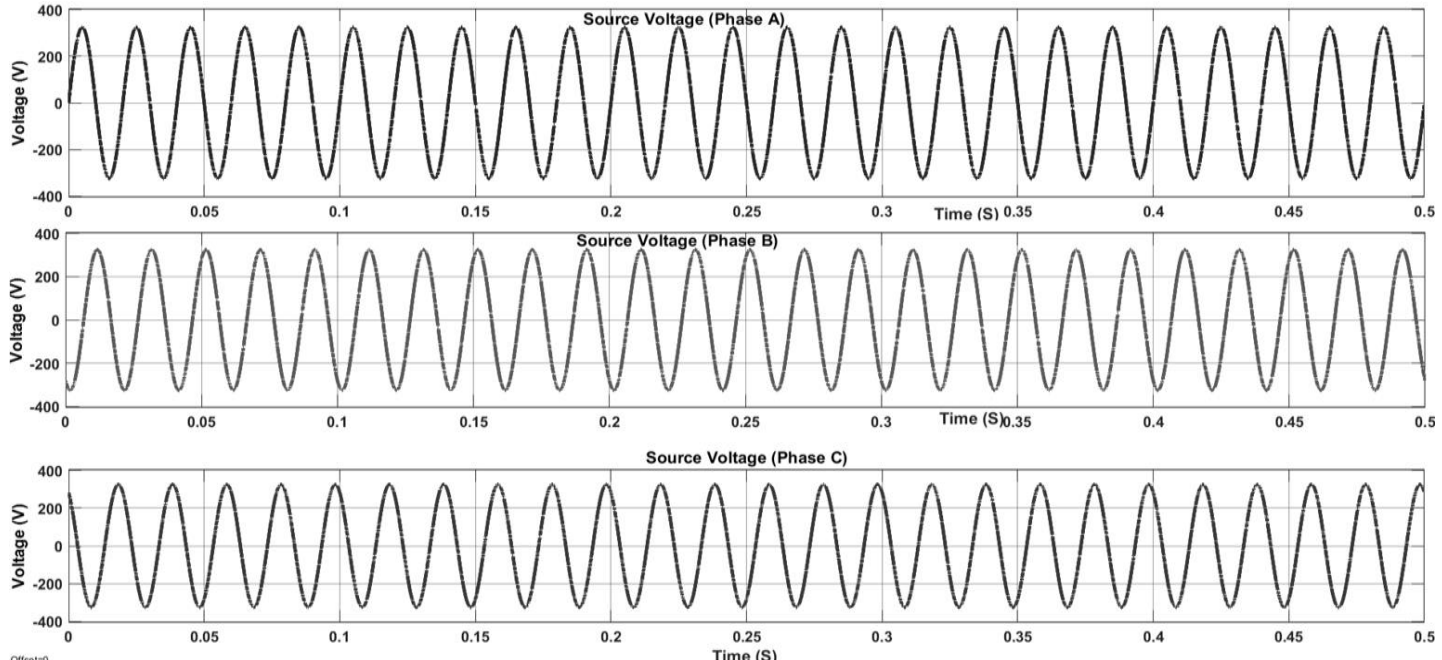

(a)
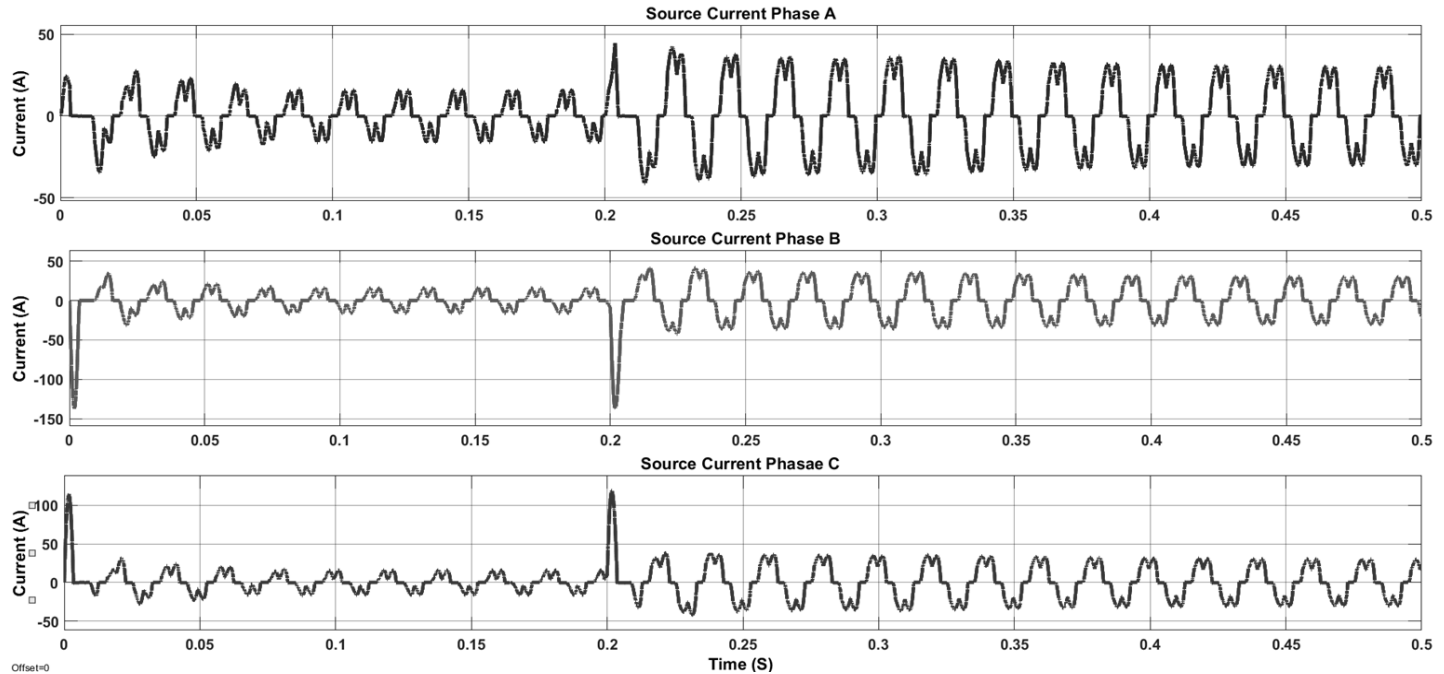

(b)

Figure 7. Voltage and current waveform for (a) three phase source voltage and (b) three phase source current
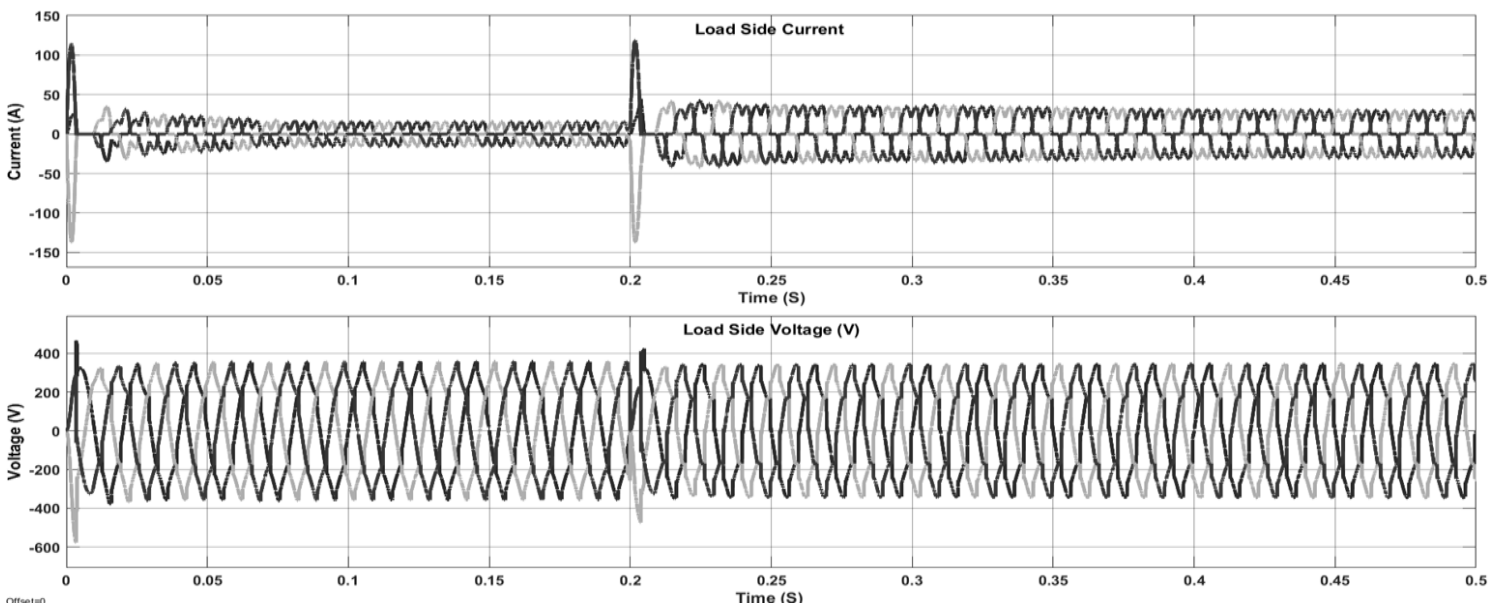

Figure 8. Load side voltages and current 


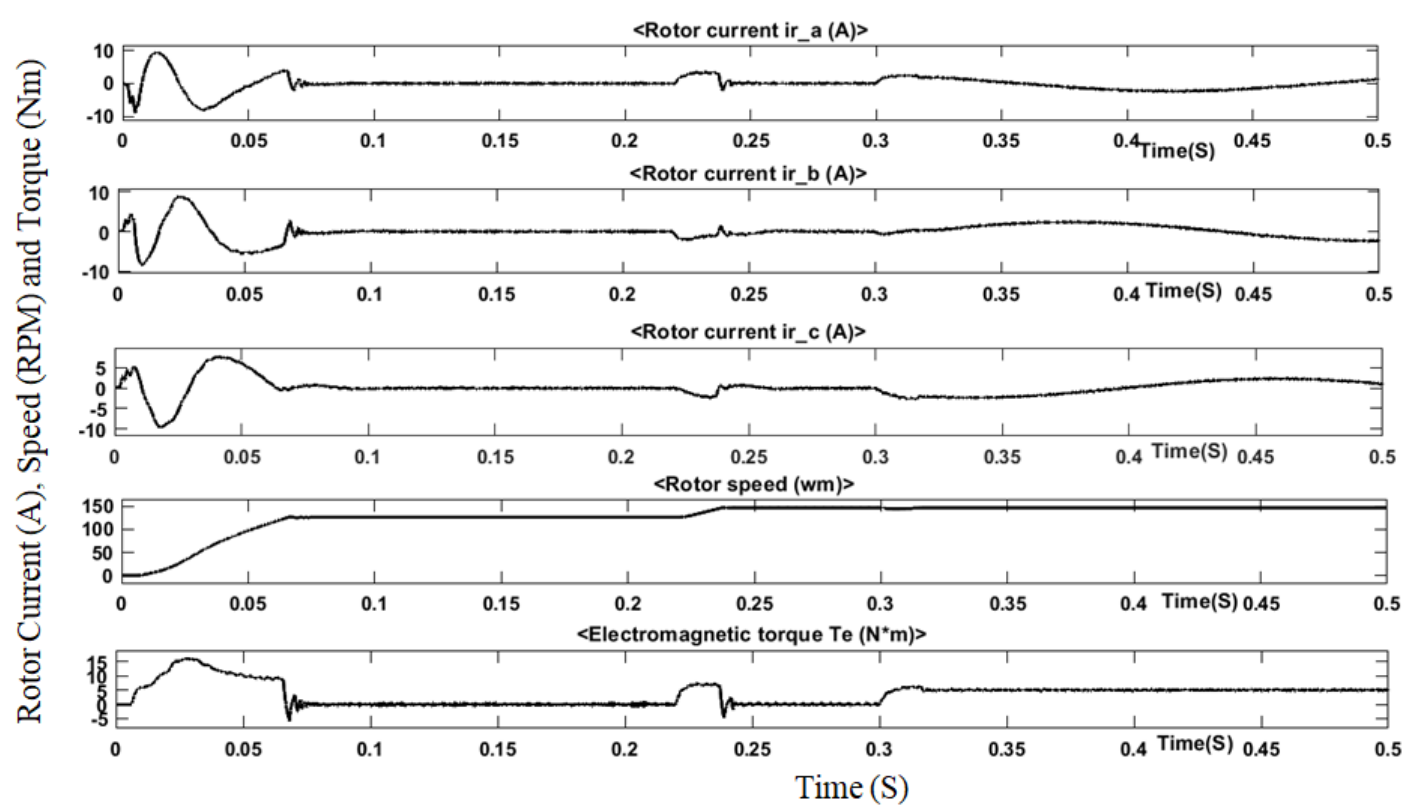

Figure 9. AC drive system-1 rotor current, speed and torque

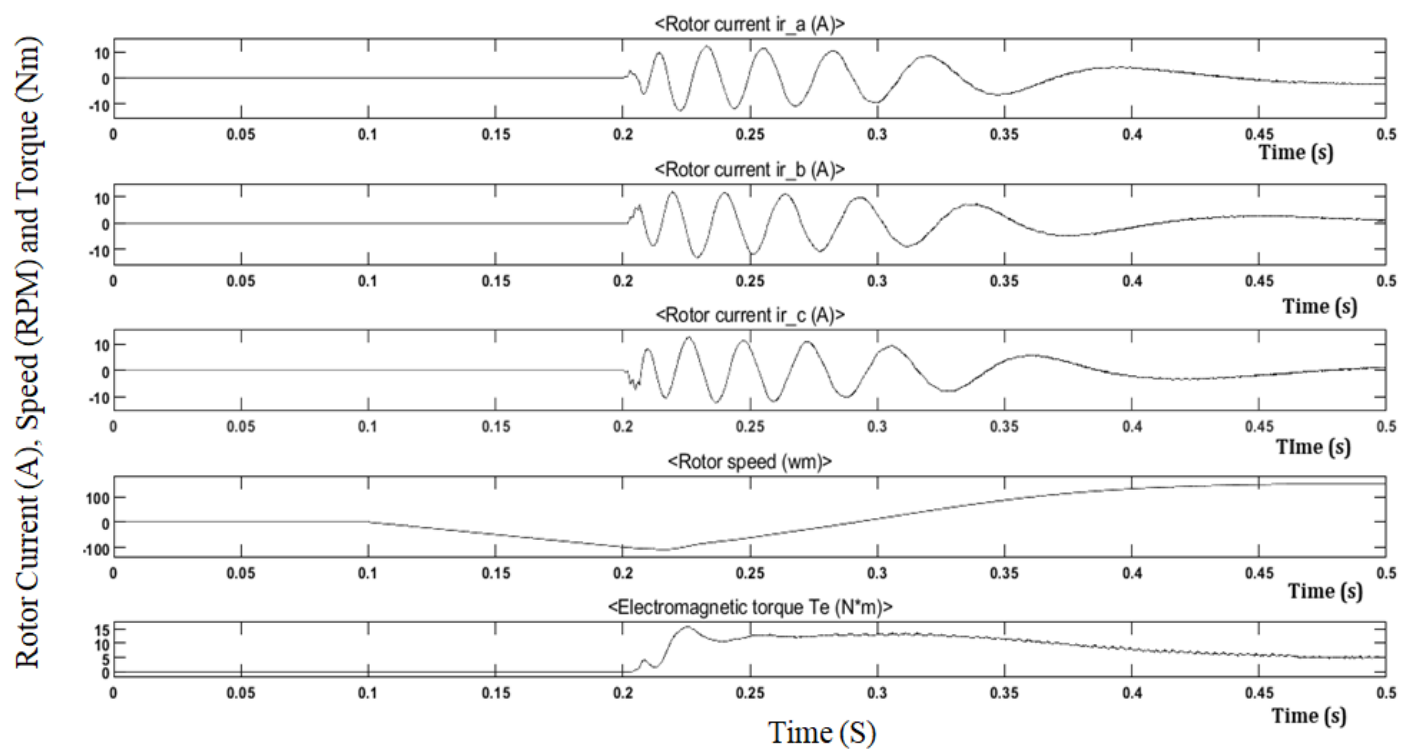

Figure 10. AC drive system-2 rotor current, speed and torque

From Figures 11 and 12, the total harmonic distortion (THD) is examined for both cases i.e. for single and multi-drive systems that increasing the drives lowers the harmonics percentage and leads to increase in current. It is noted that the \% THD in single drive system is $46.7 \%$ and multi drive system is $27.7 \%$ before the compensator is added. In both cases the \% THD is not in the recommended limit as per IEEE 519, 2004 standard. So that a shunt active power filter is connected in parallel to the system between grid and drive systems. According to the changes in the load side the filter compensates harmonics present in the current.

Total harmonics distortion (THD) is reduced by adding the filters nearly for $5 \%$ and $1.5 \%$ for both single and multi-drive system, which is the best way to drive the motors with the least harmonics present which indirectly increase the efficiency and the production. The \% THD for both the system after the filter is considered is demonstrated in Figures 13 and 14. Figure 15 shows the after adding filters for the multi drive system the voltage and current. The perfect sine wave with fewer harmonic about $2 \%$ is what we wanted to achieve after the filter. 


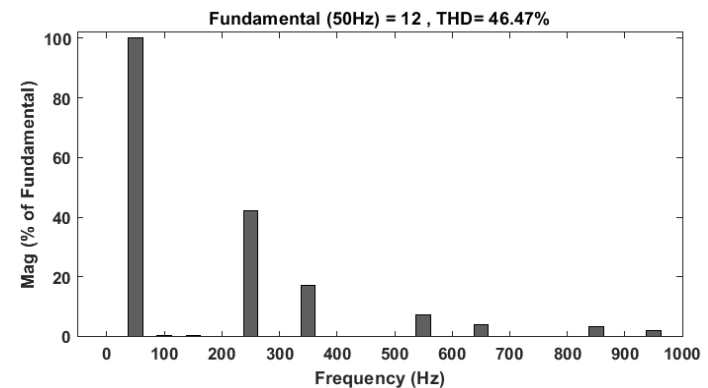

Figure $11 . \%$ of THD for single drive system

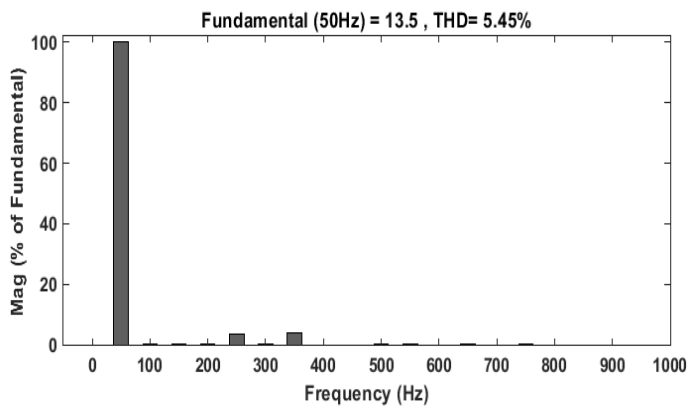

Figure 13. $\%$ of THD after considering the filter for single drive system

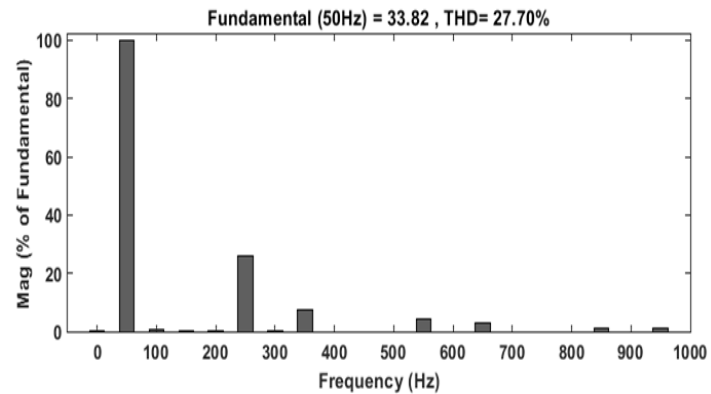

Figure $12 . \%$ of THD for multi-drive system

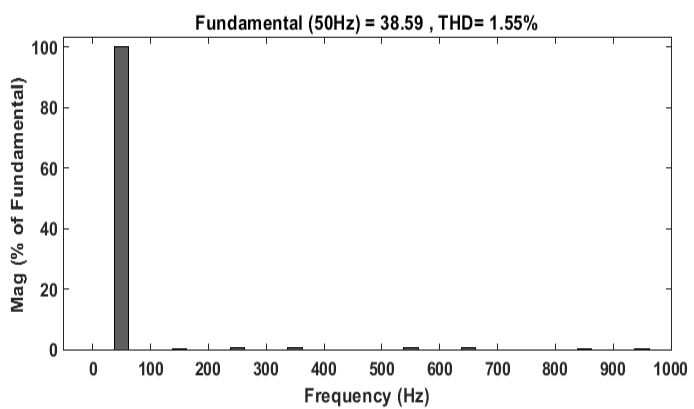

Figure 14. $\%$ of THD after considering the filter for multi-drive system

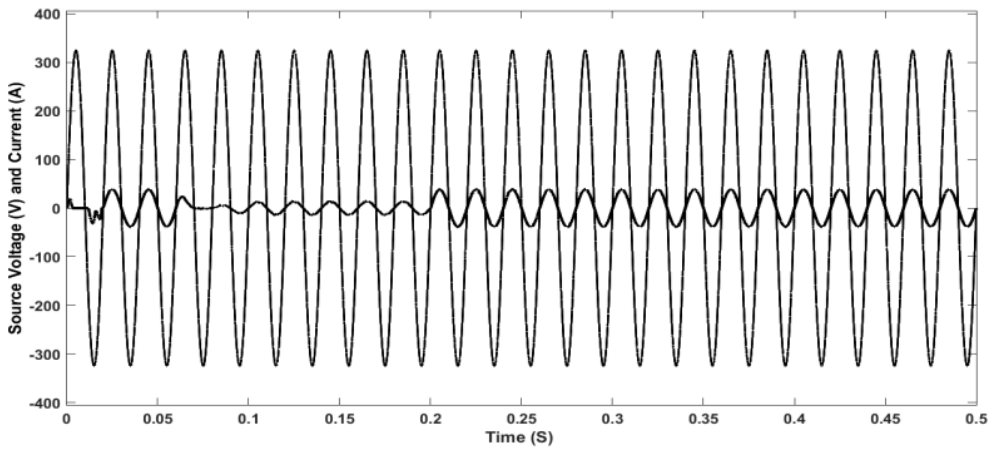

Figure 15. Source voltage and current after the filter for multi-drive system

\section{CONCLUSION}

The shunt active power filter is designed here to eliminate the harmonics due to the multi-drive variable frequency system. The induction motor is used for the variable frequency drive system. The \% THD obtained only with single drive system is $46.47 \%$. For a two-drive system the \% THD is reduced to $27.7 \%$ without adding the filter. When the filter is added the \% THD is reduced to $5.45 \%$ and $1.55 \%$ in single and multi-drive system respectively. From the simulation results it shows that in a multi-drive system the $\%$ THD is less when compared to the single drive system.

\section{REFERENCES}

[1] J. W. Kolar and T. Friedli, "The essence of three-phase PFC rectifier systems," IEEE 33rd International Telecommunications Energy Conference (INTELEC), 2011, pp. 1-27, doi: 10.1109/INTLEC.2011.6099838.

[2] T. Friedli, M. Hartmann, and J. W. Kolar, "The Essence of Three-Phase PFC Rectifier Systems - Part II," IEEE Transactions on Power Electronics, vol. 29, no. 2, pp. 543-560, 2014, doi: 10.1109/TPEL.2013.2258472.

[3] P. K. Steimer, "High power electronics innovation," presented at ICPE-ECCE Asia, pp. 1-37, 2015.

[4] W. Lee, Y. Son, and J. Ha, "Single-Phase Active Power Filtering Method Using Diode-Rectifier-Fed Motor Drive," IEEE Transactions on Industry Applications, vol. 51, no. 3, pp. 2227-2236, 2015, doi: 10.1109/TIA.2014.2365629.

[5] S. Hansen, P. Nielsen, and F. Blaabjerg, "Harmonic cancellation by mixing nonlinear single-phase and three-phase loads," IEEE Transactions on Industry Applications, vol. 36, no. 1, pp. 152-159, 2000, doi: 10.1109/28.821810. 
[6] F. Meng, W. Yang, Y. Zhu, L. Gao and S. Yang, "Load Adaptability of Active Harmonic Reduction for 12-Pulse Diode Bridge Rectifier with Active Interphase Reactor," IEEE Transactions on Power Electronics, vol. 30, no. 12, pp. 7170-7180, 2015, doi: 10.1109/TPEL.2015.2391272.

[7] P. Waide and C. U. Brunner, "Energy-efficiency policy opportunities for electric motor-driven systems," International Energy Agency, pp. 1-132, 2011, doi: 10.1787/5kgg52gb9gjd-en.

[8] P. Barbosa, C. Haederli, P. Wikstroem, M. Kauhanen, J. Tolvanen, and A. Savolainen, "Impact of motor drive on energy efficiency," Proceedings PCIM, 2007, pp. 1-6.

[9] S. V. Giannoutsos and S. N. Manias, "A Systematic Power-Quality Assessment and Harmonic Filter Design Methodology for Variable-Frequency Drive Application in Marine Vessels," IEEE Transactions on Industry Applications, vol. 51, no. 2, pp. 1909. 1919, 2015, doi: 10.1109/TIA.2014.2347453.

[10] A. Ullah, I. U. H. Sheikh, S. Arshad, and F. Saleem, "Digital Active Power Filter Controller Design for Current Harmonics in Power System," 16th International Bhurban Conference on Applied Sciences and Technology (IBCAST), 2019, pp. 384-388, doi: 10.1109/IBCAST.2019.8667169.

[11] K. Lee, D. Carnovale, D. Young, D. Ouellette, and J. Zhou, "System Harmonic Interaction Between DC and AC Adjustable Speed Drives and Cost Effective Mitigation,” IEEE Transactions on Industry Applications, vol. 52, no. 5, pp. 3939-3948, Sept.Oct. 2016, doi: 10.1109/TIA.2016.2562006.

[12] H. R. Andersen, Ruimin Tan, and Cai Kun, "3-phase AC-drives with passive front-ends with focus on the slim DC-link topology," IEEE Power Electronics Specialists Conference, 2008, pp. 3248-3254, doi: 10.1109/PESC.2008.4592454.

[13] S. Singh and B. Singh, "Optimized Passive Filter Design Using Modified Particle Swarm Optimization Algorithm for a 12-Pulse Converter-Fed LCI-Synchronous Motor Drive," IEEE Transactions on Industry Applications, vol. 50, no. 4, pp. 2681-2689, 2014, doi: 10.1109/TIA.2013.2292991

[14] M. M. Swamy, “An Electronically Isolated 12-Pulse Autotransformer Rectification Scheme to Improve Input Power Factor and Lower Harmonic Distortion in Variable-Frequency Drives," IEEE Transactions on Industry Applications, vol. 51, no. 5, pp. 39863994, 2015, doi: 10.1109/TIA.2015.2417123.

[15] S. Chiniforoosh, H. Atighechi, and J. Jatskevich, "A Generalized Methodology for Dynamic Average Modeling of High-PulseCount Rectifiers in Transient Simulation Programs," IEEE Transactions on Energy Conversion, vol. 31, no. 1, pp. 228-239, 2016, doi: 10.1109/TEC.2015.2483748.

[16] B. Singh, V. Garg and G. Bhuvaneswari, "A Novel T-Connected Autotransformer-Based 18-Pulse AC-DC Converter for Harmonic Mitigation in Adjustable-Speed Induction-Motor Drives," IEEE Transactions on Industrial Electronics, vol. 54, no. 5, pp. 2500-2511, 2007, doi: 10.1109/TIE.2007.900332

[17] H. Akagi and K. Isozaki, "A Hybrid Active Filter for a Three-Phase 12-Pulse Diode Rectifier Used as the Front End of a MediumVoltage Motor Drive," IEEE Transactions on Power Electronics, vol. 27, no. 1, pp. 69-77, 2012, doi: 10.1109/TPEL.2011.2157977.

[18] F. Zare, "Harmonics issues of three-phase diode rectifiers with a small DC link capacitor," 16th International Power Electronics and Motion Control Conference and Exposition, 2014, pp. 912-917, doi: 10.1109/EPEPEMC.2014.6980623.

[19] M. A. S. Masoum and E. F. Fuchs, "Power Quality in Power Systems and Electrical Machines," Academic Press, 2015, doi: 10.1016/B978-0-12-369536-9.X5001-3.

[20] Z. Wang, Q. Li, Y. Tang, S. Liu, and S. Dai, "Comparison of harmonic limits and evaluation of the international standards," MATEC Web of Conferences 277, 2018,doi: 10.1051/matecconf/201927703009.

[21] J. A. Pomilio and G. Spiazzi, "A low-inductance line-frequency commutated rectifier complying with EN 61000-3-2 standards," IEEE Transactions on Power Electronics, vol. 17, no. 6, pp. 963-970, 2002, doi: 10.1109/TPEL.2002.805597.

[22] S. Choi, P. N. Enjeti and I. J. Pitel, "Polyphase transformer arrangements with reduced kVA capacities for harmonic current reduction in rectifier-type utility interface," IEEE Transactions on Power Electronics, vol. 11, no. 5, pp. 680-690, 1996, doi: $10.1109 / 63.535400$

[23] H. Akagi, “Active Harmonic Filters,” Proc. of the IEEE, vol. 93, no. 12, pp. 2128-2141, 2005, doi: 10.1109/JPROC.2005.859603.

[24] X. Du, L. Zhou, H. Lu and H. Tai, "DC link active power filter for three-phase diode rectifier," IEEE Transactions on Industrial Electronics, vol. 59, no. 3, pp. 1430-1442, 2012, doi: 10.1109/TIE.2011.2167112.

[25] P. Xiao, G. K. Venayagamoorthy and K. A. Corzine, "Seven-Level Shunt Active Power Filter for High-Power Drive Systems," IEEE Transactions on Power Electronics, vol. 24, no. 1, pp. 6-13, 2009, doi: 10.1109/TPEL.2008.2005897.

[26] E. J. Delaney and R. E. Morrison, "Minimisation of interharmonic currents from a current source AC drive by means of a selective DC side active filter," IEEE Transactions on Power Delivery, vol. 10, no. 3, pp. 1584-1590, July 1995, doi: $10.1109 / 61.400943$

[27] M. Schweizer, I. Lizama, T. Friedli and J. W. Kolar, "Comparison of the chip area usage of 2-level and 3-level voltage source converter topologies," IECON 2010 - 36th Annual Conference on IEEE Industrial Electronics Society, 2010, pp. 391-396, doi: $10.1109 /$ IECON.2010.5674994.

\section{BIOGRAPHIES OF AUTHORS}

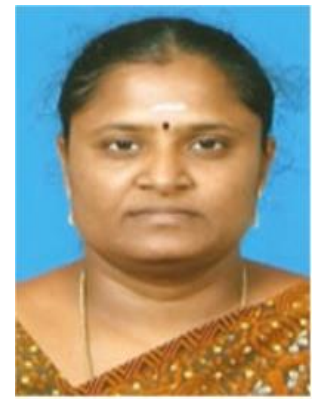

Thamizh Thentral (D) 8. SC $\mathrm{P}$ received her Bachelor of Engineering degree in Electronics and Communication Engineering from Periyar Maniammai, College of Technology for Women, Vallam, India, in 1994 under Bharathidasan University; her Master of Engineering degree in Power Electronics and Drives from Anna University (Easwari Engineering College,) Chennai, India, in 2008 and completed her $\mathrm{Ph} \mathrm{D}$. from SRM Institute of Science and Technology in 2020. She has been working as an Assistant Professor in Department of Electrical and Electronics Engineering, SRM Institute of Science and Technology, Kattankulathur since July 2012. Her research areas of interest are: Power Quality, Power Electronics Converters Smart Grid, Microgrid and Electric Drives and Control. She can be contacted at email: thentral2kuna@gmail.com. 

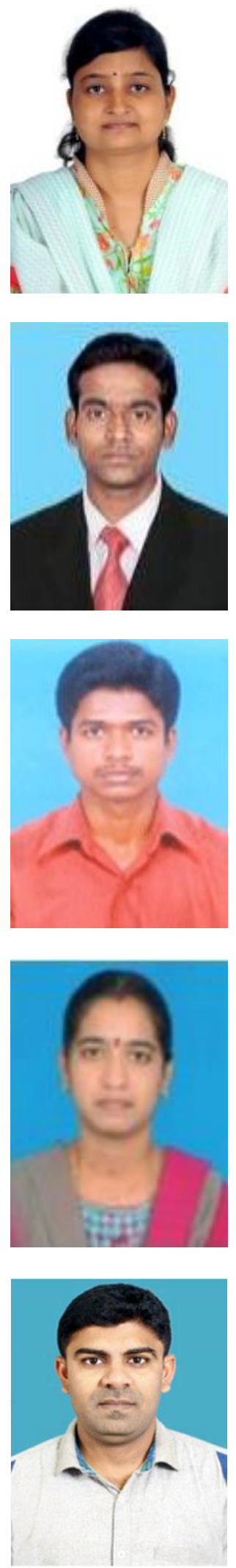

Ramya Rathakrishnan (iD) $8 \mathrm{SC}$ P Oobtained B.E(EEE) with Distn, from Anna University, Chennai, M.E(Power System Engineering) with Distn, from Anna University, Tirunelveli in the year 2007 and 2009 respectively. She obtained Ph.D. in Power Systems in December 2017 from Anna University Chennai. She is currently working as Assistant Professor in the Department of Electrical and Electronics Engineering in SRM Institute of Science and Technology, Chennai, Tamilnadu, India. Her research interests include Machine Modeling, Power System Optimization, Real Time Simulation and Power System Control.She can be contacted at email: ramyar4@srmist.edu.in.

Velu Anbalagan (iD I8 SC P received the B.E degree in Electrical and Electronics Engineering at Institute of Road and Transport Technology, Erode, Tamilnadu, India in 2010 and the M.Tech. degree in Power Electronics and Drives from SRM University, Chennai, Tamilnadu, India, in 2013. He is working as Assistant Professor in the Department of Electrical \& Electronics Engineering. He is having eight years of teaching experience. His area of interest includes Power Electronics Circuits and its Applications in, Electric Vehicles, Renewable Power Conversion Systems and HVDC Power Transmission Systems.He can be contacted at email: karthikd@ srmist.edu.in.

Karthikeyan Dhandapani (iD $8 \mathrm{SC}$ S received his B.E.degree from the Department of Electrical and Electronics Engineering of A.I.H.T College, Chennai, India (affiliated with Anna University, Chennai, India), in 2009; and his M.Tech. degree in Power Electronics and Drives from SRMIST (Formerly SRM University), Kattankulathur, India, in 2013, where he had completed his Ph.D. degree in Multilevel Inverters (2019). He is presently working as Assistant Professor in the Department of Electrical \& Electronics Engineering, SRMIST (Formerly SRM University), Kattankulathur and Chennai, India. His current research interests include Power Electronics, Multilevel Inverters, AC drives and DC drives. He is a member of various professional societies such as the IEEE, IEI and ISCA. He can be contacted at email: karthikd@ srmist.edu.in.

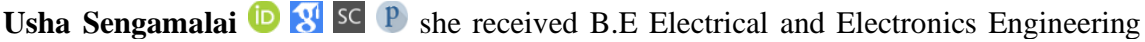
and M.E Power Electronics and Drives from Anna University, Chennai in 2007 and 2012 respectively. She Completed Ph. D from SRM Institute of science and technology in 2020, also working as an Assistant professor in the department of Electrical and Electronics Engineering SRM University. She has published more than 29 international and national journals. Her research interests include Power Electronics Converters and Stability analysis of Induction motors, Electric drive systems. She can be contacted at email: ushas@srmist.edu.in.

Palanisamy Ramasamy (D) 8 SC $\mathrm{P}$ received the B.E. degree in electrical and electronics engineering from Anna University, India, in 2011, and the M.Tech. degree in power electronics and drives and the Ph.D. degree in power electronics from the SRM Institute of Science and Technology, Chennai, India, in 2013 and 2019, respectively. He is currently working as an Assistant Professor with the Department of Electrical Engineering, SRM Institute of Science and Technology. He has published more than 95 international and national journals. His research interests include power electronics multilevel inverters, various PWM techniques for power converters, FACTS controllers, and grid connected photovoltaic systems. He can be contacted at email: palanisr@srmist.edu.in. 